\title{
Uptake of Polygenic Risk Information among Women at Increased Risk of Breast
}

\section{Cancer}

Tatiane Yanes MGC,${ }^{1,2}$ Bettina Meiser PhD, ${ }^{1}$ Rajneesh Kaur PhD, ${ }^{1}$ Maatje Scheepers-Joynt $\mathrm{PhD},{ }^{3}$ Simone McInerny BBiomedSc, ${ }^{3}$ Shelby Taylor MGC, ${ }^{3}$ Kristine Barlow-Stewart MGC $\mathrm{PhD},{ }^{4}$ Yoland Antill ${ }^{5}$ BMed MD, Lucinda Salmon ${ }^{6}$ MGC, Courtney Smyth7 MGC, Mary-Anne Young MHSc, ${ }^{3,8}$ Paul A James FRACP PhD ${ }^{3,9}$

${ }^{1}$ Prince of Wales Clinical School, Faculty of Medicine, University of New South Wales, Sydney NSW 2052, Australia

${ }^{2}$ School of Psychiatry, Faculty of Medicine, University of New South Wales, Sydney NSW 2052, Australia

${ }^{3}$ Parkville Familial Cancer Centre, Peter MacCallum Cancer Centre and the Royal Melbourne Hospital, Melbourne VIC 3000, Australia

${ }^{4}$ Northern Clinical School, Faculty of Medicine and Health, University of Sydney, Sydney NSW 2065, Australia

${ }^{5}$ Familial Cancer Clinic, Cabrini Health, Melbourne VIC 3144, Australia

${ }^{6}$ Clinical Genetics Service, Austin Hospital, Melbourne VIC 3084, Australia

${ }^{7}$ Familial Cancer Clinic, Monash Medical Centre, Melbourne VIC 3168, Australia

${ }^{8}$ Kinghorn Centre for Clinical Genomics, Garvan Institute of Medical Research, Sydney 2010, Australia

${ }^{9}$ Sir Peter MacCallum Department of Oncology, University of Melbourne, Melbourne Vic, 3052, Australia

Corresponding Author: Tatiane Yanes, Psychosocial Research Group, Lowy Cancer Research Centre C25, The University of New South Wales, UNSW Sydney, NSW 2052, Australia. Email: t.yanes@student.unsw.edu.au Fax: +61 (2) 93850033.

\section{Conflict of interest:}

This is the author manuscript accepted for publication and has undergone full peer review but has not been through the copyediting, typesetting, pagination and proofreading process, which may lead to differences between this version and the Version of Record. Please cite this article as doi: $10.1111 /$ cge.13687

This article is protected by copyright. All rights reserved. 
Bettina Meiser has a remunerated consultant role with the company Astra Zeneca with respect to an unrelated project. Astra Zeneca has not been involved in the collection or analysis of data for articles nor in writing or submitting this manuscript.

This article is protected by copyright. All rights reserved. 


\begin{abstract}
Polygenic risk scores (PRS) are increasingly being implemented to assess breast cancer risk. This study aimed to assess and determine factors associated with uptake of PRS among women at increased risk of breast cancer for whom genetic testing to date had been uninformative. Participants were recruited from the Variants in Practice study from which breast cancer PRS had been calculated. Four hundred women were notified by letter of the availability of their PRS and invited to complete a self-administered survey comprising several validated scales. Considering non-participants, uptake of PRS lies between $61.8 \%$ to 42.1\%. Multivariate logistic regression identified that women were more likely to receive their PRS if they reported greater benefits (odds ratio $[O R]=1.17, p=0.011$ ) and fewer barriers to receiving their $\mathrm{PRS}(\mathrm{OR}=0.80, \mathrm{p}=0.007)$, had completed higher level education $(\mathrm{OR}=3.32$, $p=0.004)$, and did not have daughters $(0.29, p=0.006)$. Uptake of breast cancer PRS varies according to several testing- and patient-related factors. Knowledge of these factors will facilitate the implementation of polygenic testing in clinical practice and support informed decision making by patients.
\end{abstract}

Key Words: Breast cancer, polygenic risk, uptake, psychosocial, single nucleotide polymorphism

This article is protected by copyright. All rights reserved. 


\section{Introduction:}

It is estimated that in addition to monogenic causes, a further $18 \%$ of the familial contribution to breast cancer can be explained by polygenic factors. ${ }^{1}$ When the cumulative effect of common genomic variants is summarized into a polygenic risk score (PRS), studies have found that woman in the highest quartile of polygenic distribution have at least a two-fold increased risk for the disease compared to those with a PRS in the lowest quartile. ${ }^{2-4}$ In the familial cancer setting, polygenic information can be used to subdivide the group of women with uninformative genetic testing results for monogenic causes with regard to their ongoing breast cancer risk or the risk of contralateral disease for woman previously affected. ${ }^{3}$ Based on this, and a perception of increased consumer demand for information to assist in cancer risk management, implementation of polygenic testing has begun with several commercial laboratories now offering the test. ${ }^{5,6}$

Despite commercial availability, there is limited data reporting on the implementation of polygenic breast cancer risk information and uptake of the test. Prior studies have been limited to hypothetical scenarios or based on single SNP testing. ${ }^{7-11}$ These studies have reported a high interest in SNP testing, with interest ranging from $74 \%$ to $80 \% \cdot{ }^{7-10}$ Interest in SNP testing was more consistently related to psychological factors (i.e. perceived risk and greater cancer worry), rather than sociodemographic variables, ${ }^{7-11}$ and in one study, interest was reduced among women with more negative views of the test. ${ }^{11}$ It is well documented that interest in genetic testing is often higher than actual testing uptake, ${ }^{12}$ thus these findings need to be considered with caution. Nevertheless, these studies provide the foundation to understanding decisions to pursue polygenic information.

This article is protected by copyright. All rights reserved. 
Much can be learnt from the literature on BRCA1/2 testing decisions. Studies have consistently reported that women who have higher cancer-specific anxiety are more likely to undergo $B R C A 1 / 2$ genetic testing. ${ }^{13,14}$ It has also been reported that women are more likely to seek out genetic testing if they have a greater need for certainty and lower tolerance for uncertainty. ${ }^{15,16}$ Additional qualitative studies have reported that women at high risk for breast cancer undergo BRCA1/2 genetic testing due to a sense of responsibility towards their family, particularly female relatives in younger generations. ${ }^{17-21}$ Regarding barriers to genetic testing, women have described financial concerns, ${ }^{14}$ fear of work and insurance discrimination, ${ }^{14,18,20}$ practical concerns such as difficulty taking time off from family and work obligations to attend the genetic counseling appointment and lack of access to genetics services. ${ }^{14,18,21}$

It is likely that polygenic information will soon be implemented in familial cancer clinics (FCC) as a second-tier testing for women clinically assessed at increased risk for breast cancer where testing for monogenic causes has been uninformative. ${ }^{3}$ Understanding genetic testing decisions among this group of women is key to guiding the implementation of polygenic testing in clinical practice. The aim of this study was to examine uptake of breast cancer polygenic information, and determine factors associated with uptake among women from breast cancer families with uninformative genetic testing results. We hypothesized that women who have a more negative attitude towards uncertainty, have daughters, and have higher breast-cancer-specific anxiety would be more likely to elect to receive their polygenic breast cancer information. This study was conducted as part of a prospective cohort study, which aims to assess the impact of offering polygenic breast cancer information to women at increased risk for the disease. ${ }^{22}$

This article is protected by copyright. All rights reserved. 


\section{Material and Methods}

\section{Study design and participants}

The study protocol has been described elsewhere. ${ }^{22}$ Participants were recruited from an established cohort, the Variants in Practice (ViP) study. ${ }^{23}$ The ViP cohort is made up of women affected by breast cancer and their unaffected relatives. Prior to enrollment in the ViP study, all families had undergone a clinical assessment, genetic counselling and genetic testing at an FCC in the Australian states of Victoria and Tasmania. Additional genotyping of 62 breast-cancer- associated SNPs was conducted through the ViP study, from which an individual PRS and relative risk (RR) for breast cancer were generated. ${ }^{24}$

Additional eligibility criteria for this study included: women aged $\geq 18$ years who had received uninformative genetic testing results of high- and moderate-risk breast cancer genes. No exclusions were made based on personal history of breast cancer. This study was approved by the Peter MacCallum Cancer Centre (HREC/16/PMCC/2) and the Tasmanian Research Ethics Committee (H0016395).

\section{Recruitment and data collection}

Women meeting these criteria were mailed the study information and consent form, an educational pamphlet describing polygenic breast cancer risk (Supplementary material 1 ), ${ }^{25}$ and a response sheet. Those who opted into the study completed a baseline questionnaire (Q1). The study information sheet notified individuals that they would be eligible to enroll in the study regardless of their decision to receive their PRS; thus both women who wished to receive their PRS and those declining this offer were eligible to participate. Reminder letters

This article is protected by copyright. All rights reserved. 
and phone calls were made to participants who did not return the study response sheet and who failed to complete Q1 as required.

Participants who indicated intention to receive their PRS in Q1 were contacted by the study team and an appointment was booked at one of the six participating FCCs located in the Australian states of Victoria and Tasmania. Participants who failed to attend three appointments without contacting the FCC were categorized as a 'decliner'.

\section{Disclosure of PRS}

Participants received their PRS by attending an in-person appointment with a qualified genetic health professional (e.g. genetic counselor, clinical geneticist, or oncologist with training in familial cancer). The appointments included disclosure of the participant's personalized breast cancer PRS, a discussion about the implications of their PRS in line with participants' personal and/or family history of breast cancer, and breast cancer risk management strategies. A graphical representation of participants' PRS, including their relative risk of breast cancer compared to the Australian general population and the impact of lifestyle factors (alcohol consumption and body mass index greater than 30) were used when explaining PRS results. ${ }^{24}$

\section{Measures}

Clinical characteristics such as personal breast cancer history and number of affected relatives were available through the ViP database. ${ }^{23}$ The baseline survey elicited the following data:

This article is protected by copyright. All rights reserved. 
Demographic characteristics - sociodemographic data included age, country of origin, marital status, educational level, language spoken at home, children (including number of daughters), and previous attendance at an FCC.

Intention to receive PRS - participants were asked whether they would like to receive their PRS with three response options: 'Yes, and please contact me to arrange an appointment', 'No, and do not contact me to arrange an appointment' and 'Unsure, I would like more information before making this decision. Please contact me to discuss this further.'

Perceived severity of breast cancer - was assessed with one item. Participants were asked to rate the severity of breast cancer from 'not serious at all' (1) to 'extremely serious' (5). ${ }^{26}$

Perceived breast cancer risk - Participants were asked to rate their own breast cancer risk relative to an average person the same age and gender, and a person with a similar family history of breast cancer using a scale from 'much lower' (1) to 'much higher' (5). Participants also self-rated their chances of developing breast cancer in the future using a visual analogue scale from 'no chance' $(0 \%)$ to 'certainly will develop breast cancer' $(100 \%) .{ }^{26}$

Perceived benefits - eight items were adapted from Kasparian, et al. ${ }^{26}$ to assess perceived benefits of receiving one's PRS (e.g. learn about my children's risk). Scores range from 0 to 24, with higher scores indicating higher perceived benefits of the test (Cronbach's alpha $=0.71)$.

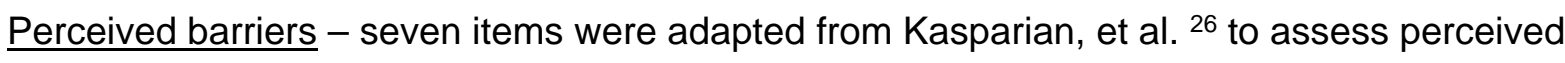
barriers to receiving one's PRS (e.g. concern about the impact of genetic information on my family). Scores range from 0 to 21, with higher scores indicating higher perceived barriers to receiving their PRS (Cronbach's alpha=0.82).

This article is protected by copyright. All rights reserved. 
Self-efficacy - seven items were adapted from Fisher, et al. ${ }^{27}$ to assess confidence in receiving one's PRS despite 'obstacles'. Scores range from 7 to 35, with higher scores indicating higher ability to access the test (Cronbach's alpha $=0.78$ ).

Uncertainty avoidance - was assessed using the eight-item Attitudes Towards Uncertainty scale. ${ }^{15}$ Total scores range from 1 to 5 , with higher scores indicating a more negative attitude towards uncertainty (Cronbach's alpha=0.81).

Knowledge of familial breast cancer and polygenic risk -10 true-false items were adapted from Erblich, et al. ${ }^{28}$ and Ondrusek, et al. ${ }^{29}$ to assess knowledge of hereditary breast cancer and polygenic risk. A total score was calculated by summing the total number of correct answers (range 0 to 10), with higher scores indicating more knowledge of familial breast cancer (Cronbach's alpha=0.63). Self-reported knowledge of polygenic risk was also assessed, with participates asked to rate how much information they had read about the common risk variants used to assess breast cancer risk with responses ranging from "nothing" to "a lot of information".

Breast cancer anxiety - was measured using the Impact of Events Scale (IES), a measure of intrusion and avoidance toward a stressor, in this case being at risk for breast cancer. ${ }^{30} \mathrm{~A}$ total score was obtained by summing the items (range 0 to 75 ), with a higher score indicating more breast cancer anxiety (Cronbach's=0.94).

General anxiety and depression - were assessed using the Hospital Anxiety and Depression Scale (HADS). A total scale score was obtained by summing each item (range 0 to 42), with a higher score indicating more general anxiety and depression (Cronbach's alpha=0.86).

This article is protected by copyright. All rights reserved. 
Stressful life events - was assessed using the 12-item List of Threatening Experiences, which measures common threatening life experiences, including serious illness and death in the family. ${ }^{31}$ Threatening life events may affect anxiety and distress levels and were measured as a potential confounding variable.

\section{Statistical analysis}

Data were analyzed using SPSS 25. Descriptive statistics were used to describe the sociodemographic, clinical and psychological characteristics of the sample. Univariate logistic regression was conducted between predictor variables and uptake of PRS. Variables that had significance levels of $p<0.25$ in the univariate analysis were included in the multivariate regression model. Logistic regression analysis was then employed to identify variables that were independently associated with uptake of PRS using a backwards elimination strategy until only those with $p$-values of $<0.05$ were included in the final model. Stressful life events and demographic measures, including previous FFC attendance, were included as potential confounding variables. Model fit was assessed using the HosmerLemeshow goodness of fit test.

\section{Results:}

Response rate and participation bias

[Insert Table 1: Demographic and clinical characteristics for PRS receivers, decliners, and the total sample $(n=208)]$

Recruitment occurred from August 2016 until August 2018. Of the 400 invited to the study, 8 were deceased, 217 consented to participate and 208 completed the baseline questionnaire,

This article is protected by copyright. All rights reserved. 
yielding a participation rate of 53.1\%. Demographic and clinical characteristics of participants are shown in Table 1. The mean age of participants at baseline was 52.3 years $(S D=13.1)$, the majority were born in Australia (87.4\%) and spoke English at home (97.1\%). Approximately half of the participants had a personal history of breast cancer $(n=106$, 51.0\%). Most participants had previously attended an FCC to discuss their personal and/or family history of breast cancer $(n=124,59.9 \%)$, with $97(46.6 \%)$ having personally undergone BRCA1/2 genetic testing for which results were uninformative. Among affected women the mean age of their first breast cancer diagnosis was 45.1 years (range: 24 to 75 years).

As per the study protocol, reminder letters and phone calls were made to participants who did not return the study invitation letter. Out of the 184 women who did not participate in the study, only 59 (32.1\%) declined to participate, either by returning the study invitation letter or upon follow-up contact. The remaining 124 participants could not be contacted, and it is not known if these individuals received the study invitation letter or if they were not interested in participating in the study.

Of the 184 non-participants, 105 (57.1\%) had a personal history of breast cancer and 93 (50.5\%) had personally undergone BRCA1/2 genetic testing and received uninformative results (Table 2). Participants and non-participants did not differ by age, personal history of breast cancer, number of affected relatives, and whether they had previously undergone BRCA1/2 genetic testing (Table 2).

[Insert Table 2: Demographic and clinical characteristics of study participants and nonparticipants] 
Uptake of PRS

Out of the 208 participants who completed the baseline questionnaire, $180(86.5 \%)$ indicated interest in receiving their personal PRS, 10 (4.8\%) declined this offer, and 18 (8.7\%) were unsure. By the time of study completion, 165 had attended an FCC and received their PRS ('receivers'), and 43 had declined this offer ('decliners'). Considering the additional 184 participants who declined to participate in the study, and hence did not complete the baseline survey or receive their results, uptake of PRS was $42.1 \%$ ( $n=165$ out of 392). However, since only 59 non-participants returned the study response sheet, it is not possible to exclude whether the remaining 124 non-participants received the study invitation letter known or if they were not interested in participating in the study. Thus, the true uptake of PRS for breast cancer risk in this study lies between $61.8 \%$ and $42.1 \%$.

\section{Perceived benefits and barriers to receiving PRS}

[Insert Figure 1: Percentages of receivers and decliners endorsing perceived benefits and barriers to receiving their personal PRS as 'somewhat' or 'very much' influencing their decision to receive PRS $(n=208)]$

Figure 1 shows the percentages of participants who selected 'somewhat' or 'very much' for the perceived benefits and barriers to receiving their personal PRS separately for receivers and decliners. There were several differences in how receivers and decliners rated these items. For example, in nearly all cases receivers endorsed higher practical benefits to receiving their PRS when compared to decliners. Specifically, the majority of receivers endorsed the following statements as influencing their decision to receive their PRS: 'get information about how to manage my risk of developing cancer' (94.5\%), 'be more certain

This article is protected by copyright. All rights reserved. 
about my cancer risk' (90.3\%), and 'plan for the future' (86.1\%). In comparison, fewer decliners rated these items as influencing their decision, $80.5 \%, 75.0 \%$ and $68.3 \%$, respectively (Figure 1 ).

Similarly, there were large differences in how the two groups rated the potential barriers to receiving their PRS, with decliners endorsing higher emotional barriers when compared to the receivers. For example, $52.6 \%$ of decliners reported concerns about their ability to cope with the information emotionally, whereas only $34.8 \%$ of receivers endorsed this item as a potential barrier. In comparison to receivers (15.0\%), decliners also had higher fatalistic concerns about breast cancer with $34.2 \%$ of women in this group endorsing the following statement: 'it wouldn't change my belief that cancer is inevitable' as somewhat or very much influencing their decision not to receive their PRS. There was only one item, 'possible impact on insurance', for which endorsement was lower in the decliner group (34.2\%) compared to receivers $(46.6 \%)$.

Knowledge of familial cancer and PRS

When participants were asked to rate how much information they had read on the common risk variants associated with breast cancer risk, $48.8 \%$ of decliners and $37.8 \%$ of receivers indicated they had read nothing or almost nothing. Similarly, $44.2 \%$ of decliners and $47.6 \%$ of receivers indicated they had read some information, while fewer women reported having read a fair amount or a lot of information, $7.0 \%$ and $14.6 \%$ respectively.

[Insert Figure 2: Percentage of correctly answered knowledge questions about familial breast cancer and polygenic risk by receiver and decliners.]

This article is protected by copyright. All rights reserved. 
There were differences in the rate of correct answers between decliners and receivers. For example, 59.4\% of women who received their PRS correctly identified the following statement: 'if a woman learns that she does not have a fault in the BRCA1 or BRCA2 genes, that means the breast cancer in her family cannot be hereditary' as false. In comparison only $29.3 \%$ of decliners correctly categorized this statement (Figure 2). Similarly, $69.1 \%$ of receivers correctly responded to: 'there is more than one DNA change that can increase a woman's risk for breast cancer', while less than half (45.2\%) of decliners correctly answered this question.

\section{Predictors of PRS uptake}

[Insert Table 3: Univariate and multi-variate logistic regression assessing for predictors of PRS uptake]

The association between the predictor variables and uptake of PRS are shown in Table 3. Model fit as assessed with Hosmer-Lemeshow goodness-of-fit test which indicated adequate fit ( $p=0.685)$. None of the psychological measures (IES and HADS), clinical history, or having read information about common risk variants were associated with uptake of PRS in the univariate logistic regression (Table 3). Although significant in the univariate logistic regression, uncertainty avoidance and self-efficacy were no longer statistically significant when controlling for the other predictor variables (Table 3).

After adjusting for other predictor variables and potential confounders, the multivariate logistic regression suggest uptake of PRS was significantly associated with perceiving fewer barriers to the test $(\mathrm{OR}=0.80,95 \% \mathrm{Cl}=0.69-0.94, \mathrm{p}=0.007)$, higher perceived benefits of the test $(\mathrm{OR}=1.17,95 \% \mathrm{Cl}=1.04-1.30, \mathrm{p}=0.011)$, not having daughters $(\mathrm{OR}=0.29,95 \%$

This article is protected by copyright. All rights reserved. 
$\mathrm{Cl}=0.12-0.70, \mathrm{p}=0.006)$, and having completed bachelors education $(\mathrm{OR}=3.32,95 \%$

$\mathrm{Cl}=1.46-7.55, \mathrm{p}=0.004)$.

\section{Discussion:}

To our knowledge this is the one of the first prospective studies to explore women's decision to receive polygenic breast cancer risk information. Our study demonstrated that women at increased risk of breast cancer for whom previous genetic testing has been uninformative are interested in accessing updated genetic information that may clarify their level of risk. Our reported uptake figure (61.8\% to $42.1 \%)$ is in line with mean uptake of $B R C A 1 / 2$ testing (59\%) reported in a previous systematic review of breast cancer genetic testing decisions. ${ }^{32}$ Despite all families in this study having previously undergone BRCA1/2 genetic testing, less than $61.8 \%$ of participants chose to receive updated genetic risk information in the form of PRS. Reasons for participants declining to receive their PRS remains unknown. However, findings from our study may have shed light on factors that may have influenced women to receive their PRS.

Previous studies into early adopters of new genetic technology such as BRCA1/2 genetic testing $^{33}$ and whole genome sequencing ${ }^{34}$ identified that these individuals were more likely to be information seekers, with higher formal education. Additionally, early adopters will seek new information in the hope to improve their understanding about disease risk and health management, and will choose to proceed with testing even if faced with uncertainty about the potential risk and usefulness of information. ${ }^{33,34}$ These findings are reflected among our participants, with women who received their PRS being more likely to have completed higher level education, reported greater benefits and fewer barriers to receiving their results. In contrast, women who opted not to receive their PRS were more likely to have done so due to

This article is protected by copyright. All rights reserved. 
concerns about their emotional response and in the absence of balanced medical information.

Women's self-reported perception of the benefits and barriers to receiving polygenic information was strongly associated with uptake of results. Compared to decliners, receivers reported higher practical benefits to receiving their PRS, such as planning for the future and accessing information to manage breast cancer risk. In comparison, decliners reported higher emotional barriers such as coping with information emotionally and concerns about the impact of information on family members. These findings are consistent with studies of genetic testing decisions, with a previous systematic review identifying perceived benefits and barriers of the test as one of the strongest predictors of testing uptake. ${ }^{35}$ Such findings suggest that any interventions aimed at facilitating genetic testing decisions should involve an exploration of the extent the individual believes the test will be beneficial for them, as well as concerns and potential barriers to undergoing the test.

In contrast to our hypothesis, breast cancer anxiety and attitudes towards uncertainty were not associated with uptake of polygenic breast cancer information. Similarly, clinical history such as personal history and family history of breast cancer was not associated with uptake of PRS. Unexpectedly, we also found that women without daughters were more likely to receive their personal PRS compared to those with daughters. This finding remained even when adjusted for demographic factors such as age, educational level, and marital status. It is possible to interpret this finding in light of the multivariate model, where women who declined to receive their results also reported fewer benefits and more concerns about receiving their PRS. It is likely participants with daughters declined to receive their results to "protect" their relatives as they felt the benefits to receiving this information did not outweigh 
the potential for negative outcomes. It is also possible that prior experiences with breast cancer, such as a death in the family or having an affected mother confounded these results. For example, women who experience a death in a close relative may have greater fatalistic beliefs about breast cancer, and this experience may have influenced their decision not to pursue additional genetic testing. Our study did not permit an extensive assessment of family history and its impact on PRS uptake. Future studies should aim to further explore the association between lived experiences and uptake of PRS.

As PRS continues to be implemented in clinical practice, it is important to conduct additional studies to assess how women respond to receiving this complex information. These studies should assess women's understanding of PRS, and their psychological and behavioral outcomes. New frameworks will also need to be developed to ensure PRS are effectively communicated. Such frameworks will need to account for monogenic risk genes and other breast cancer risk factors such as family history and lifestyle. Studies assessing the different applications of PRS should also be conducted, including as a modifier of high- and moderate-risk breast cancer risk genes, ${ }^{36,37}$ and for population screening programs. ${ }^{38-40}$ Each application of PRS will have its own unique set of research questions which will need to be investigated.

Results should be interpreted in light of the study's strengths and limitations. Firstly, this cohort was made up of a diverse group of women that included individuals with and without a personal history of breast cancer, as well those who had attended an FCC in the past and those who had not. However, nearly all women were born in Australia and spoke English at home, thus generalizability to cultural and linguistic minorities is limited. Secondly, we reported a range of PRS (61.8\% and $42.1 \%)$ based on non-participants. Attempts were

This article is protected by copyright. All rights reserved. 
made to ensure individuals were informed that they were eligible to participate in the study regardless of their decision to receive their PRS. Despite this, it is likely that individuals selfselected to participate based on interest in receiving their PRS, and therefore, uptake figures may not be completely representative of women offered polygenic testing. The results from our regression model should also be interpreted with caution as the number of decliners $(n=43)$ does not meet the events per predictor variable rule. ${ }^{41}$ However, we included all eligible variables in our regression model based on the theoretical framework used, and on significance level cut offs as their inclusion is justified due to statistically significant associations. ${ }^{42}$ Lastly, it should be noted that research is still ongoing to identify SNPs associated with breast cancer risk ${ }^{43}$ and to determine the best performing PRS. ${ }^{44,45}$ Hence, it is possible the present PRS will need to be updated in the future. Despite these limitations, our findings point to potential areas for intervention to facilitate genetic testing decisions that include improving knowledge of familial breast cancer and PRS and exploring perceived benefits and barriers to accessing polygenic information. Additionally, our findings indicate a high interest in receiving personalized breast cancer PRS, suggesting some women who receive uninformative genetic testing results will continue to seek information to clarify their risk level.

\section{Acknowledgements:}

Firstly, we thank all the women who participated in the study. We would also like to thank all the clinicians at the participating FCCs for accommodating this study and arranging appointment for participants to receive their PRS. This study is supported by a grant from the Cancer Council of New South Wales (ID: 1079897). TY is supported by a National Health and Medical Research Council (NHMRC) and National Breast Cancer Foundation

This article is protected by copyright. All rights reserved. 
postgraduate scholarship (ID: 1133049), and a Translational Cancer Research Institute PhD Top-up Scholarship. BM is supported by an NHMRC Senior Research Fellowship Level B (ID 1078523).

\section{Availability of data and materials:}

The data that support the findings of this study are available on request from the corresponding author. The data are not publicly available due to privacy or ethical restrictions.

ORCID:

Tatiane Yanes: https://orcid.org/0000-0002-3905-3025

This article is protected by copyright. All rights reserved. 


\section{References:}

1. Michailidou $\mathrm{K}$, et al. Association analysis identifies 65 new breast cancer risk loci. Nature. 2017.

2. Mavaddat N, et al. Prediction of Breast Cancer Risk Based on Profiling With Common Genetic Variants. J Natl Cancer Inst. 2015;107(5).

3. Sawyer S, et al. A Role for Common Genomic Variants in the Assessment of Familial Breast Cancer. J Clin Oncol. 2012;30(35):4330-4336

4. Evans DG, et al. The impact of a panel of 18 SNPs on breast cancer risk in women attending a UK familial screening clinic: a case-control study. J Med Genet. 2016.

5. Black M, et al. Validation of a Polygenic R isk Score for Breast Cancer in Unaffected Caucasian Women Referred for Genetic Testing. J Clin Oncol. 2018;36.

6. Hughes E, et al. Development and validation of a residual risk score to predict breast cancer risk in unaffected women negative for mutations on a multi-gene hereditary cancer panel. J Clin Oncol. 2017;35(15_suppl):1579-1579.

7. Anderson $\mathrm{AE}$, et al. Interest and Informational Preferences Regarding Genomic Testing for Modest Increases in Colorectal Cancer Risk. Public Health Genom. 2014;17(1):48-60.

8. Graves KD, et al. Interest in Genetic Testing for Modest Changes in Breast Cancer Risk: Implications for SNP Testing. Public Health Genom. 2011;14(3):178-189.

9. Leventhal K-G, et al. "Is it really worth it to get tested?": primary care patients' impressions of predictive SNP testing for colon cancer. J Genet Couns. 2013;22(1):138-151.

10. Howe R, et al. Personalized Medicine Through SNP Testing for Breast Cancer Risk: Clinical Implementation. J Genet Couns. 2015;24(5):744-751.

This article is protected by copyright. All rights reserved. 
11. Hall MJ, et al. Interest in genomic SNP testing for prostate cancer risk: a pilot survey. Hered Cancer Clin Pract. 2015;13.

12. Sanderson SC, et al. What Can Interest Tell Us about Uptake of Genetic Testing? Intention and Behavior amongst Smokers Related to Patients with Lung Cancer. Public Health Genom. 2010;13(2):116-124.

13. Andrews L, et al. Psychological impact of genetic testing for breast cancer susceptibility in women of Ashkenazi Jewish background: a prospective study. Genet Test. 2004;8(3):240-247.

14. Foster $\mathrm{C}$, et al. Non-uptake of predictive genetic testing for BRCA1/2 among relatives of known carriers: attributes, cancer worry, and barriers to testing in a multicenter clinical cohort. Genet Test. 2004;8(1):23-29.

15. Braithwaite D, et al. Intention to participate in predictive genetic testing for hereditary cancer: the role of Attitude toward Uncertainty. Psychol Health. 2002;17:761-772.

16. Croyle RT, et al. Need for certainty and interest in genetic testing. Womens Health. 1995;1(4):329-339.

17. Hallowell N, et al. Genetic testing for women previously diagnosed with breast/ovarian cancer: Examining the impact of BRCA1 and BRCA2 mutation searching. Genet Test. 2002;6(2):79-87.

18. Ramirez AG, et al. Interest, awareness, and perceptions of genetic testing among Hispanic family members of breast cancer survivors. Ethn Dis. 2006;16(2):398-403.

19. Jeffers $L$, et al. Maximising survival: the main concern of women with hereditary breast and ovarian cancer who undergo genetic testing for BRCA1/2. Eur $\mathrm{J}$ Oncol Nurs. 2014;18(4):411-418.

This article is protected by copyright. All rights reserved. 
20. Wakefield CE, et al. Attitudes toward genetic testing for cancer risk after genetic counseling and decision support: a qualitative comparison between hereditary cancer types. Genet Test. 2007;11(4):401-411.

21. Culver J, et al. Participation in Breast Cancer Genetic Counseling: The Influence of Educational Level, Ethnic Background, and Risk Perception. J Genet Couns. 2001;10(3):215-231.

22. Yanes T, et al. Psychosocial and behavioral impact of breast cancer risk assessed by testing for common risk variants: protocol of a prospective study. BMC Cancer. 2017;17(1):491.

23. Variants in Practice (VIP). Peter MacCallum Cancer Centre https://www.petermac.org/research/clinical-research-trials/clinical-research/familialcancer-research-centre/vip-variants. Accessed 2019.

24. Forrest LE, et al. High-risk women's risk perception after receiving personalized polygenic breast cancer risk information. J Community Genet. 2018.

25. Kaur R, et al. Development and pilot testing of a leaflet informing women with breast cancer about genomic testing for polygenic risk. Fam Cancer. 2018.

26. Kasparian NA, et al. Genetic testing for melanoma risk: a prospective cohort study of uptake and outcomes among Australian families. Genet Med. 2009;11(4):265-278.

27. Fisher $\mathrm{A}$, et al. Factors influencing intention to undergo whole genome screening in future healthcare: A single-blind parallel-group randomised trial. Prev Med. 2012;55:514-520.

28. Erblich J, et al. Development and validation of a Breast Cancer Genetic Counseling Knowledge Questionnaire. Patient Educ Couns. 2005;56(2):182-191.

This article is protected by copyright. All rights reserved. 
29. Ondrusek $\mathrm{N}$, et al. Development of a knowledge scale about breast cancer and heredity (BCHK). Breast Cancer Res Treat. 1999;53(1):69-75.

30. Horowitz M, et al. Impact of Events Scale: A measure of subjective stress. Psychosom Med. 1979;41:209-218.

31. Brugha $\mathrm{T}$, et al. The List of Threatening Experiences: the reliability and validity of a brief life events a a questionnaire. Acta Psychiatr Scand. 1990;82:77-81.

32. Ropka ME, et al. Uptake rates for breast cancer genetic testing: a systematic review. Cancer Epidemiol Biomarkers Prev. 2006;15(5):840-855.

33. Armstrong K, et al. Early adoption of BRCA1/2 testing: who and why. Genet Med. 2003;5(2):92-98.

34. Facio FM, et al. Motivators for participation in a whole-genome sequencing study: implications for translational genomics research. European journal of human genetics : EJHG. 2011;19(12):1213-1217.

35. Sweeny K, et al. Predictors of Genetic Testing Decisions: A Systematic Review and Critique of the Literature. J Genet Couns. 2014;23(3):263-288.

36. Muranen TA, et al. Genetic modifiers of CHEK2*1100delC-associated breast cancer risk. Genet Med. 2017;19(5):599-603.

37. Kuchenbaecker KB, et al. Evaluation of Polygenic Risk Scores for Breast and Ovarian Cancer Risk Prediction in BRCA1 and BRCA2 Mutation Carriers. J Natl Cancer Inst. 2017;109(7).

38. Evans DGR, et al. Breast cancer pathology and stage are better predicted by risk stratification models that include mammographic density and common genetic variants. Breast Cancer Res Treat. 2019;176(1):141-148.

This article is protected by copyright. All rights reserved. 
39. Shieh $\mathrm{Y}$, et al. Breast Cancer Screening in the Precision Medicine Era: Risk-Based Screening in a Population-Based Trial. J Natl Cancer Inst. 2017;109(5).

40. Esserman LJ, et al. The WISDOM Study: breaking the deadlock in the breast cancer screening debate. npj Breast Cancer. 2017;3(1):34.

41. Peduzzi $P$, et al. A simulation study of the number of events per variable in logistic regression analysis. J Clin Epidemiol. 1996;49(12):1373-1379.

42. Vittinghoff $\mathrm{E}$, et al. Relaxing the rule of ten events per variable in logistic and Cox regression. Am J Epidemiol. 2007;165(6):710-718.

43. Milne RL, et al. Identification of ten variants associated with risk of estrogen-receptornegative breast cancer. Nat Genet. 2017.

44. Lall K, et al. Polygenic prediction of breast cancer: comparison of genetic predictors and implications for risk stratification. BMC Cancer. 2019;19(1):557.

45. Khera AV, et al. Genome-wide polygenic scores for common diseases identify individuals with risk equivalent to monogenic mutations. Nat Genet. 2018;50(9):12191224.

This article is protected by copyright. All rights reserved. 
Figure legends:

Figure 1: Percentages of receivers and decliners endorsing perceived benefits and barriers to receiving their personal PRS as 'somewhat' or 'very much' influencing their decision to receive PRS $(n=208)$

Figure 2: Percentage of correctly answered knowledge questions about familial breast cancer and polygenic risk by receiver and decliners.

This article is protected by copyright. All rights reserved. 


\section{Perceived Benefits}

Help research

Allow family members to learn about their cancer risk

Learn about my children's cancer risk

Get information about how to manage my risk of developing cancer

Be more certain about my cancer risk

Plan for the future

Confirm my belief that I have a genetic change related to cancer

Have the information for decisions about having children in the future

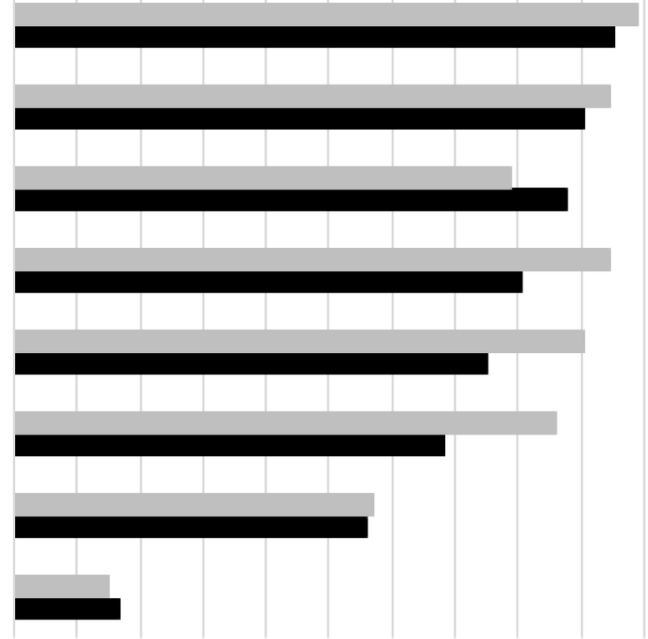

$0 \% 10 \% 20 \% 30 \% 40 \% 50 \% 60 \% 70 \% 80 \% 90 \% 100 \%$

\section{Perceived Limitations}

Concern about coping with the information emotionally

Concern about the impact of the genomic information on my family members

Concern that the information is not accurate

The possible impact on insurance

It wouldn't change my belief that cancer is inevitable

The hassle of attending an appointment at the $\mathrm{FCC}$

It conflicts with my religious, cultural and/or spiritual beliefs

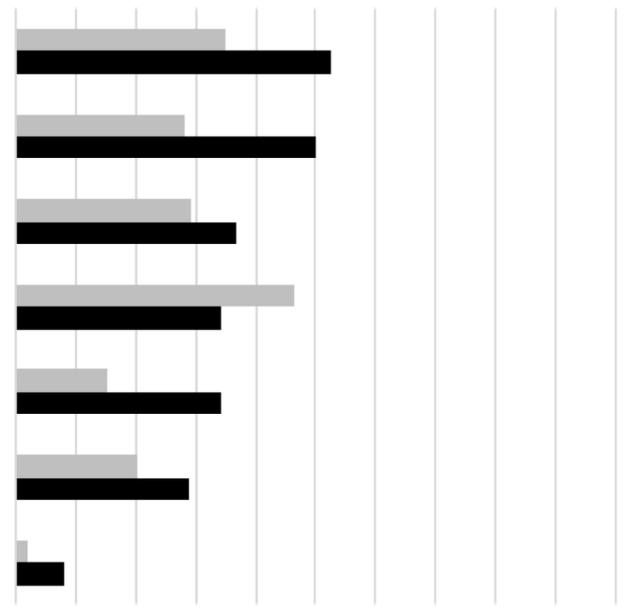

$0 \% 10 \% 20 \% 30 \% 40 \% 50 \% 60 \% 70 \% 80 \% 90 \% 100 \%$

- Receivers - Decliners

CGE_13687_Figure 1 benefits and barriers to receiving PRS.tif 
If a woman has a high risk for breast there are screening and preventative options available

A wo man may be at increased risk for breast cancer if she has several close relatives with breast cancer

It is possible to be diagnosed with breast cancer solely due to chance

All women at high risk for breast cancer will develop breast cancer

The interpretation of a high or low risk is the same for everyone

There is more than one DNA change that can increase a woman's risk for breast cancer

A wo man can only inherit DNA changes associated with breast cancer risk from her mother

If a woman learns that she does not have a fault in the BRCA1 or BRCA2 genes, that means the breast cancer in her family cannot be hereditary

Most women who develop breast cancer do not have family history of the disease

Common riskvariants associated with breast cancer risk also increases a woman's risk for ovarian cancer

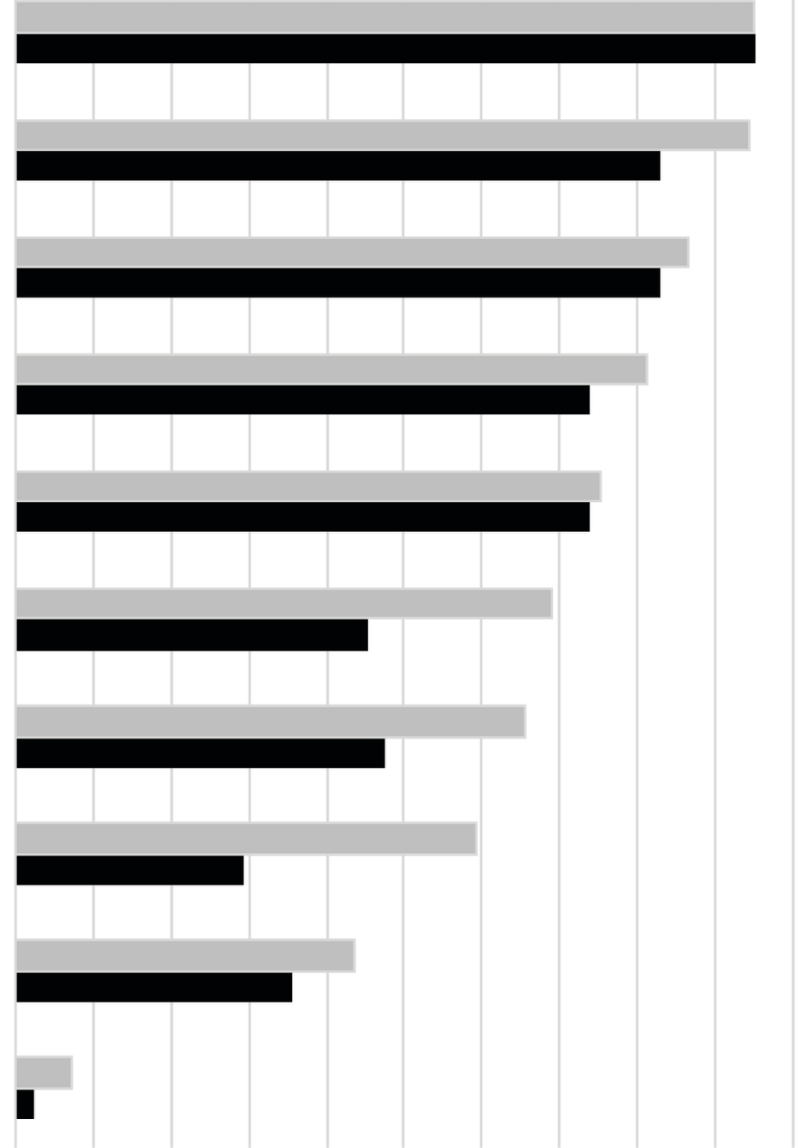

$0 \% \quad 10 \% 20 \% 30 \% 40 \% 50 \% 60 \% 70 \% 80 \% 90 \% 100 \%$

neceiver Decliner

CGE_13687_Figure 2 knowledge questions.tif

This article is protected by copyright. All rights reserved. 


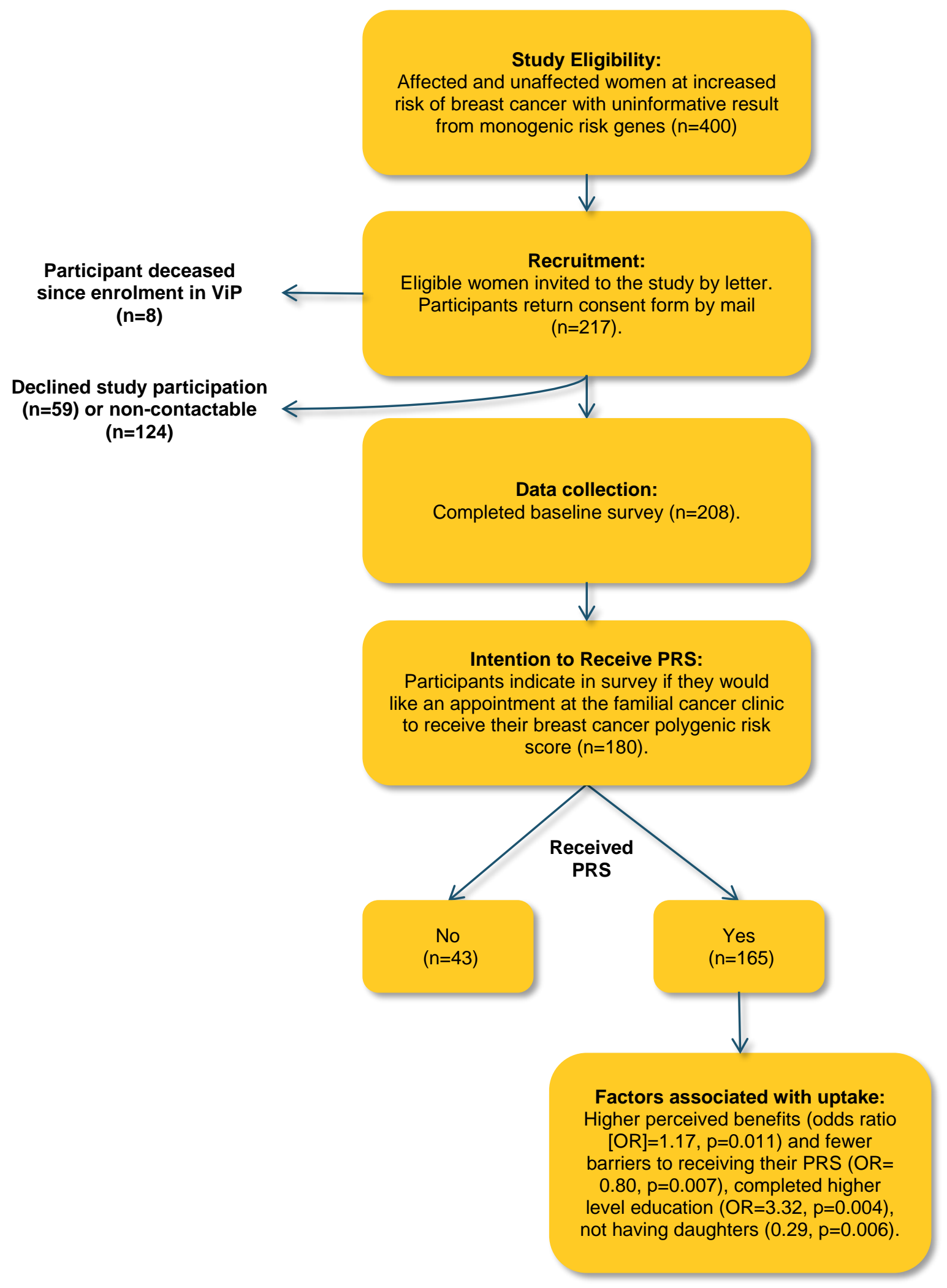

This article is protected by copyright. All rights reserved. 
Table 1: Demographic and clinical characteristics for PRS receivers, decliners, and the total sample $(n=208)$

\begin{tabular}{|c|c|c|c|c|}
\hline Variable & Level & $\begin{array}{l}\text { Receivers, } \\
\text { n (\%) }\end{array}$ & $\begin{array}{l}\text { Decliners, } \\
\text { n (\%) }\end{array}$ & $\begin{array}{c}\text { Total } \\
\text { Sample, } \\
\text { n (\%) }\end{array}$ \\
\hline \multirow{6}{*}{ Age (years) } & $18-29$ & $6(3.7)$ & $2(4.7)$ & $8(3.9)$ \\
\hline & $30-39$ & $25(15.5)$ & $3(7.0)$ & $28(13.6)$ \\
\hline & $40-49$ & $44(27.3)$ & $10(23.3)$ & $54(26.2)$ \\
\hline & $50-59$ & $42(25.8)$ & $15(34.9)$ & $57(27.7)$ \\
\hline & $60-69$ & $33(20.5)$ & $6(14.0)$ & $39(18.9)$ \\
\hline & $>70$ & $13(8.1)$ & $7(16.3)$ & $20(9.7)$ \\
\hline \multirow{2}{*}{ Has daughters } & No & $77(46.7)$ & $11(25.6)$ & $88(42.3)$ \\
\hline & Yes & $88(53.3)$ & $32(74.4)$ & $120(57.7)$ \\
\hline \multirow{3}{*}{ Employment status } & Employed & $110(66.5)$ & $26(60.4)$ & $136(66.0)$ \\
\hline & Unemployed & $23(14.1)$ & $6(14.0)$ & $28(13.6)$ \\
\hline & Retired & $30(18.4)$ & $11(25.6)$ & $42(20.4)$ \\
\hline \multirow{2}{*}{$\begin{array}{l}\text { Occupation health } \\
\text { care professional }\end{array}$} & No & $142(87.1)$ & $36(85.7)$ & $174(85.3)$ \\
\hline & Yes & $20(12.3)$ & $6(14.3)$ & $30(14.7)$ \\
\hline \multirow{2}{*}{ Marital status } & Single & $55(33.5)$ & $10(23.3)$ & $65(31.4)$ \\
\hline & Married/De Facto & $109(66.5)$ & $33(76.7)$ & $142(68.6)$ \\
\hline \multirow{3}{*}{ Education level } & High School and Below & $29(17.7)$ & $13(30.2)$ & $42(20.3)$ \\
\hline & Certificate & $39(23.8)$ & $16(37.2)$ & $55(26.6)$ \\
\hline & Bachelor and Above & $96(58.5)$ & $14(32.6)$ & $110(53.1)$ \\
\hline \multirow{2}{*}{ Birthplace } & Australia & $142(86.6)$ & $39(90.7)$ & $181(87.4)$ \\
\hline & Other & $22(13.4)$ & $4(9.3)$ & $26(12.6)$ \\
\hline \multirow{2}{*}{$\begin{array}{l}\text { Language spoken at } \\
\text { home }\end{array}$} & English & $159(97.5)$ & $41(95.3)$ & $200(97.1)$ \\
\hline & Other & $4(2.5)$ & $2(4.7)$ & $6(2.9)$ \\
\hline \multirow{2}{*}{ Breast cancer history } & Affected & $84(50.9)$ & $22(51.2)$ & $106(51.0)$ \\
\hline & Unaffected & $81(49.1)$ & $21(48.8)$ & $102(49.0)$ \\
\hline \multirow{4}{*}{$\begin{array}{l}\text { Total number of FDR } \\
\text { and SDR diagnosed } \\
\text { with breast cancer }\end{array}$} & 0 & 25 (15.2) & $7(16.3)$ & $31(15.0)$ \\
\hline & 1 & $40(24.4)$ & $16(37.2)$ & $63(30.4)$ \\
\hline & 2 & $56(34.2)$ & $9(20.9)$ & $64(30.9)$ \\
\hline & $3+$ & $43(26.2)$ & $11(25.6)$ & $49(23.8)$ \\
\hline \multirow{3}{*}{$\begin{array}{l}\text { Attended FCC in the } \\
\text { past }\end{array}$} & Yes & $106(64.6)$ & $22(51.2)$ & $128(61.8)$ \\
\hline & No & $44(26.8)$ & $19(44.2)$ & $63(30.4)$ \\
\hline & Unsure & $14(8.5)$ & $2(4.6)$ & $16(7.7)$ \\
\hline \multirow{3}{*}{$\begin{array}{l}\text { Intention to receive } \\
\text { PRS at baseline }\end{array}$} & Yes & $158(95.8)$ & $22(51.2)$ & $180(86.5)$ \\
\hline & No & $0(0)$ & $10(23.3)$ & $10(4.8)$ \\
\hline & Unsure & $7(4.3)$ & $11(25.6)$ & $18(8.7)$ \\
\hline
\end{tabular}

This article is protected by copyright. All rights reserved. 
Table 2: Demographic and clinical characteristics of study participants and nonparticipants

\begin{tabular}{|c|c|c|c|c|c|c|c|c|}
\hline & \multicolumn{2}{|c|}{ Consented } & \multicolumn{2}{|c|}{$\begin{array}{c}\text { Non- } \\
\text { participants } \\
\text { (excl. known } \\
\text { deceased (8) }\end{array}$} & \multicolumn{3}{|c|}{ Test Statistic } \\
\hline & & $\mathbf{N}$ & $\%$ & $\mathbf{N}$ & $\%$ & $x^{2}$ & df & $\mathrm{p}$ \\
\hline \multirow{6}{*}{ Age $\left(\right.$ years) ${ }^{\dagger}$} & $18-29$ & 5 & $2.4 \%$ & 4 & $2.2 \%$ & \multirow{6}{*}{7.1} & \multirow{6}{*}{5} & \multirow{6}{*}{0.21} \\
\hline & $30-39$ & 25 & $12.0 \%$ & 23 & $12.5 \%$ & & & \\
\hline & $40-49$ & 46 & $22.1 \%$ & 38 & $20.7 \%$ & & & \\
\hline & $50-59$ & 61 & $29.3 \%$ & 46 & $25.0 \%$ & & & \\
\hline & $60-69$ & 44 & $21.2 \%$ & 31 & $16.8 \%$ & & & \\
\hline & $>70$ & 27 & $13.0 \%$ & 42 & $22.8 \%$ & & & \\
\hline \multirow{2}{*}{ Phx breast/DCIS } & Affected & 106 & $51.0 \%$ & 105 & $57.1 \%$ & \multirow{2}{*}{1.5} & \multirow{2}{*}{1} & \multirow{2}{*}{0.23} \\
\hline & Unaffected & 102 & $49.0 \%$ & 79 & $42.9 \%$ & & & \\
\hline \multirow{4}{*}{$\begin{array}{l}\text { Total number of FDR } \\
\text { and SDR with breast } \\
\text { cancer or DCIS }\end{array}$} & 0 & 31 & $14.9 \%$ & 38 & $20.7 \%$ & \multirow{4}{*}{2.5} & \multirow{4}{*}{3} & \multirow{4}{*}{0.48} \\
\hline & 1 & 67 & $32.2 \%$ & 57 & $31.0 \%$ & & & \\
\hline & 2 & 61 & $29.3 \%$ & 52 & $28.3 \%$ & & & \\
\hline & $3+$ & 49 & $23.6 \%$ & 37 & $20.1 \%$ & & & \\
\hline \multirow{2}{*}{$\begin{array}{l}\text { Clinical BRCA mutation } \\
\text { detection testing with a } \\
\text { participating FCC? }\end{array}$} & Yes & 97 & $46.6 \%$ & 93 & $50.5 \%$ & \multirow{2}{*}{0.6} & \multirow{2}{*}{1} & \multirow{2}{*}{0.44} \\
\hline & No & 111 & $53.4 \%$ & 91 & $49.5 \%$ & & & \\
\hline
\end{tabular}

This article is protected by copyright. All rights reserved. 
Table 3: Univariate and multi-variate logistic regression assessing for predictors of PRS uptake

\begin{tabular}{|c|c|c|c|c|c|c|}
\hline \multirow[b]{2}{*}{ Predictor Variable } & \multirow[b]{2}{*}{$\begin{array}{l}\text { Receivers } \\
\quad \mathrm{N}(\%)\end{array}$} & \multirow[b]{2}{*}{$\begin{array}{l}\text { Decliners } \\
\text { N (\%) }\end{array}$} & \multicolumn{2}{|c|}{$\begin{array}{l}\text { Univariate Logistic } \\
\text { Regression }\end{array}$} & \multicolumn{2}{|c|}{$\begin{array}{l}\text { Multi-variate logistic } \\
\text { regression }\end{array}$} \\
\hline & & & $\begin{array}{c}\text { OR } \\
(95 \% \mathrm{Cl})\end{array}$ & $\begin{array}{c}P \\
\text { value }\end{array}$ & $\begin{array}{c}\text { OR } \\
(95 \% \mathrm{Cl})\end{array}$ & $\begin{array}{c}P \\
\text { value }\end{array}$ \\
\hline Have daughters & $\begin{array}{c}53.3 \% \text { have } \\
\text { daughter }\end{array}$ & $\begin{array}{c}\text { 74.4\% have } \\
\text { daughters }\end{array}$ & $\begin{array}{c}0.39 \\
(0.19-0.82)\end{array}$ & 0.015 & $\begin{array}{c}0.29 \\
(0.12-0.70)\end{array}$ & 0.006 \\
\hline $\begin{array}{l}\text { Have personal history of } \\
\text { breast cancer }\end{array}$ & $50.9 \%$ Yes & $51.2 \%$ Yes & $\begin{array}{c}0.920 \\
(0.47-1.80)\end{array}$ & 0.809 & - & - \\
\hline Level of Education & $\begin{array}{c}58.5 \% \\
\text { completed a } \\
\text { bachelor's } \\
\text { degree }\end{array}$ & $\begin{array}{c}32.6 \% \\
\text { completed a } \\
\text { bachelor's } \\
\text { degree }\end{array}$ & $\begin{array}{c}2.92 \\
(1.44-5.95)\end{array}$ & 0.003 & $\begin{array}{c}3.32 \\
(1.46-7.55)\end{array}$ & 0.004 \\
\hline Predictor Variable & $\begin{array}{l}\text { Receivers } \\
\text { Mean (S.D.) }\end{array}$ & $\begin{array}{c}\text { Decliners } \\
\text { Mean (S.D.) }\end{array}$ & $\begin{array}{c}\text { OR } \\
(95 \% \mathrm{Cl})\end{array}$ & $\begin{array}{c}P \\
\text { value }\end{array}$ & $\begin{array}{l}\text { Adjusted } \\
\text { OR } \\
(95 \% \mathrm{Cl})\end{array}$ & $\begin{array}{c}P \\
\text { value }\end{array}$ \\
\hline $\begin{array}{l}\text { Total number of FDR } \\
\text { and SDR diagnosed } \\
\text { with breast cancer }\end{array}$ & $1.8(1.2)$ & $1.6(1.2)$ & $\begin{array}{c}1.13 \\
(0.85-1.5)\end{array}$ & 0.395 & - & \\
\hline $\begin{array}{l}\text { Perceived Severity of } \\
\text { Breast Cancer }\end{array}$ & $4.4(0.79)$ & $4.4(0.92)$ & $\begin{array}{c}1.01 \\
(0.67-1.55)\end{array}$ & 0.931 & - & - \\
\hline Perceived Risk & $3.4(0.8)$ & $3.3(0.8)$ & $\begin{array}{c}1.01 \\
(0.67-1.55)\end{array}$ & 0.931 & - & - \\
\hline Self-Efficacy & $27.1(4.6)$ & $24.4(5.9)$ & $\begin{array}{c}1.11 \\
(1.04-1.20)\end{array}$ & 0.003 & NS & \\
\hline $\begin{array}{l}\text { Perceived benefits of } \\
\text { the test }\end{array}$ & $10.4(3.1)$ & $9.4(3.8)$ & $\begin{array}{c}1.14 \\
(1.02-1.25)\end{array}$ & 0.024 & $\begin{array}{c}1.17 \\
(1.04-1.30)\end{array}$ & 0.011 \\
\hline $\begin{array}{l}\text { Perceived barriers to } \\
\text { the test }\end{array}$ & $2.3(2.1)$ & $3.0(3.1)$ & $\begin{array}{c}0.86 \\
(0.75-0.99)\end{array}$ & 0.031 & $\begin{array}{c}0.80 \\
(0.69-0.94)\end{array}$ & 0.007 \\
\hline Uncertainty & $4.0(0.6)$ & $3.7(0.7)$ & $\begin{array}{c}1.97 \\
(1.1-3.3)\end{array}$ & 0.012 & NS & \\
\hline Knowledge & $6.8(1.8)$ & $5.6(2.2)$ & $\begin{array}{c}1.34 \\
(1.12-1.59)\end{array}$ & 0.001 & NS & \\
\hline HADS Total Scale & $7.8(5.5)$ & $7.5(5.5)$ & $\begin{array}{c}1.1 \\
(0.95-1.07)\end{array}$ & 0.720 & - & - \\
\hline IES Total Scale & $9.5(13.9)$ & $9.9(14.0)$ & $\begin{array}{c}0.10 \\
(0.97-1.10)\end{array}$ & 0.867 & - & - \\
\hline
\end{tabular}

This article is protected by copyright. All rights reserved. 


\section{University Library}

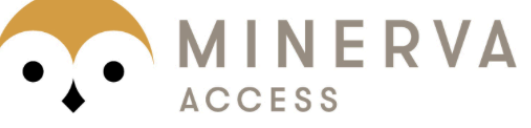

A gateway to Melbourne's research publications

Minerva Access is the Institutional Repository of The University of Melbourne

Author/s:

Yanes, T;Meiser, B;Kaur, R;Scheepers-Joynt, M;Mclnerny, S;Taylor, S;Barlow-Stewart, K;Antill, Y;Salmon, L;Smyth, C;Young, M-A;James, PA

Title:

Uptake of polygenic risk information among women at increased risk of breast cancer

Date:

2019-12-25

\section{Citation:}

Yanes, T., Meiser, B., Kaur, R., Scheepers-Joynt, M., Mclnerny, S., Taylor, S., Barlow-Stewart, K., Antill, Y., Salmon, L., Smyth, C., Young, M. -A. \& James, P. A. (2019). Uptake of polygenic risk information among women at increased risk of breast cancer. CLINICAL GENETICS, 97 (3), pp.492-501. https://doi.org/10.1111/cge.13687.

Persistent Link:

http://hdl.handle.net/11343/286783 